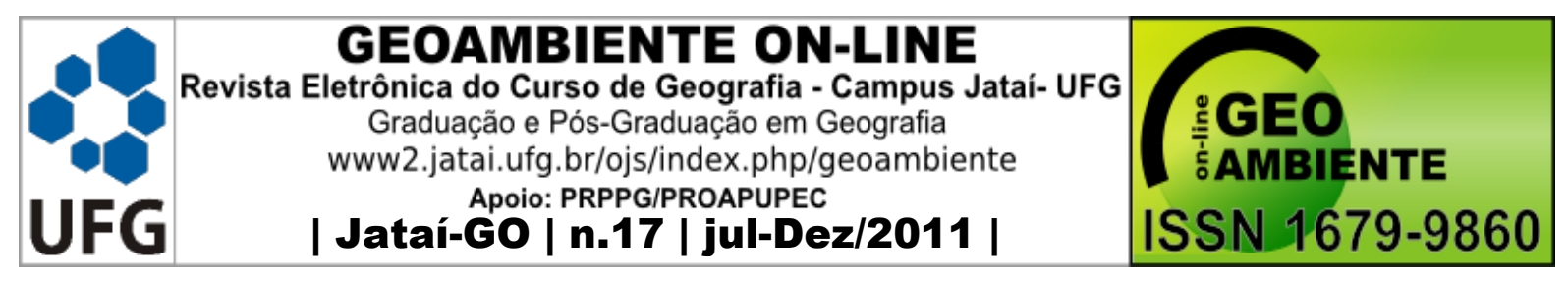

\title{
ÁGUAS SUBTERRÂNEAS, ATIVIDADES POTENCIALMENTE CONTAMINANTES E O APORTE DO GEOPROCESSAMENTO NA DEFINIÇÃO DE CONFLITOS
}

\author{
Fabiano André Marion' \\ (1- Universidade Estadual do Oeste do Paraná - Campus Fco Beltrão. Rua Maringá, 1200, \\ Bairro Vila Nova, CxP. 371 - CEP 85605-010 - Francisco Beltrão - PR. \\ Professor Colaborador - Geógrafo e Mestre em Geomática pela UFSM, Doutorando em \\ Geografia pela UFPR. E-mail: fabiano_marion@yahoo.com.br).
}

\section{Resumo}

$\mathrm{O}$ artigo tem como objetivo identificar as atividades potencialmente contaminantes, com o apoio do geoprocessamento, e confrontá-las com a vulnerabilidade natural das águas subterrâneas no Campus da Universidade Federal de Santa Maria (UFSM) - RS. Nas avaliações ambientais por geoprocessamento, identificou-se que a maioria das atividades potencialmente contaminantes ocorrem sobre áreas de alta e média vulnerabilidade natural à contaminação, ou seja, são 85 hectares com eminente risco de contaminação. Esses resultados servirão de base a planos de conservação das águas subterrâneas, integrados às diretrizes do Plano Diretor do Campus Universitário da UFSM.

Palavras-chave: Sistema Aqüífero Guarani; recursos hídricos subterrâneos; Plano Diretor;

\section{Abstract \\ GROUNDWATER, POTENTIALLY CONTAMINATING ACTIVITIES AND THE CONTRIBUTION OF GEOPROCESSING IN THE DEFINITION OF CONFLICT}

The article, have as objective, identify potentially contaminating activities, and compare them with the natural vulnerability of groundwater by geoprocessing in Campus of Universidade Federal de Santa Maria (UFSM) - RS. In geoprocessing for environmental assessments, it was found that the majority of potentially contaminating activities occur on areas of high and medium natural vulnerability to contamination, ie, they are 85 hectares with imminent risk of

\footnotetext{
Artigo recebido para publicação em 25 de Agosto de 2011

Artigo aprovado para publicação em 20 de Dezembro de 2011
} 


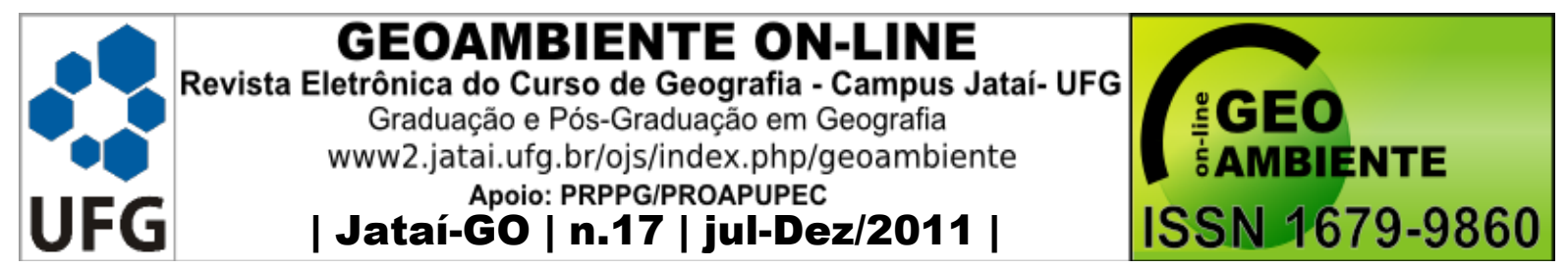

contamination. These results provide a basis for conservation planning of groundwater integrated with the guidelines of the Campus city plan of the UFSM.

Keywords: Guarani Aquifer System; groundwater hydric resources; city plan;

\section{Résumé}

\section{EAUX SOUTERRAINES, ACTIVITÉS POTENTIELLEMENT CONTAMINANTES ET LA CONTRIBUTÍON DU GÉOPROCESSUS DANS LA DÉFINITION DU CONFLITS}

L'article vise à identifier les activités potentiellement contaminantes, avec le soutien du géoprocessus, et à les comparer avec la vulnérabilité naturelle des eaux souterraines, au Campus de l'Universidade Federal de Santa Maria (UFSM) - RS. Dans les évaluations environnementales par geóprocessus, il a été constaté que la majorité des activités potentiellement contaminantes se produisent dans les zones de grande et moyenne vulnérabilité à la contamination naturelle, c'est à dire, qu'il existe 85 hectares avec un risque imminent de contamination. Ces résultats servirant de base à des plans de conservation des eaux souterraines, intégrés aux lignes directices du Plan Directeur du Campus Universitaire de la UFSM.

Mots-clés: Système Aquifère Guarani; ressources hydriques souterraines, Plan Directeur;

\section{Introdução}

O conhecimento das características naturais do meio aqüífero é indispensável para o estabelecimento de sua potencialidade e suscetibilidade à contaminação. Entretanto, a identificação e a localização de atividades produtoras de cargas potencialmente poluidoras, decorrentes da ação antropogênica, em áreas sobrejacentes ao aqüífero, é fundamental ao se estudar a questão das águas subterrâneas e determinar o seu risco de contaminação.

Dessa forma, estudos de susceptibilidade à contaminação, deixaram de ser apenas de vulnerabilidade natural e passaram a ser reconhecidos também como um ensaio de uso e ocupação do solo, já que, neste caso, contam não só com dados referentes às características naturais do aqüífero, como também, com dados referentes à intervenção antrópica.

Uma caracterização mais aproximada da idéia de risco de poluição das águas subterrâneas consiste na associação e interação da vulnerabilidade natural do aqüífero com a carga poluidora aplicada no solo ou em sub-superfície. Isso significa que se pode ter uma 


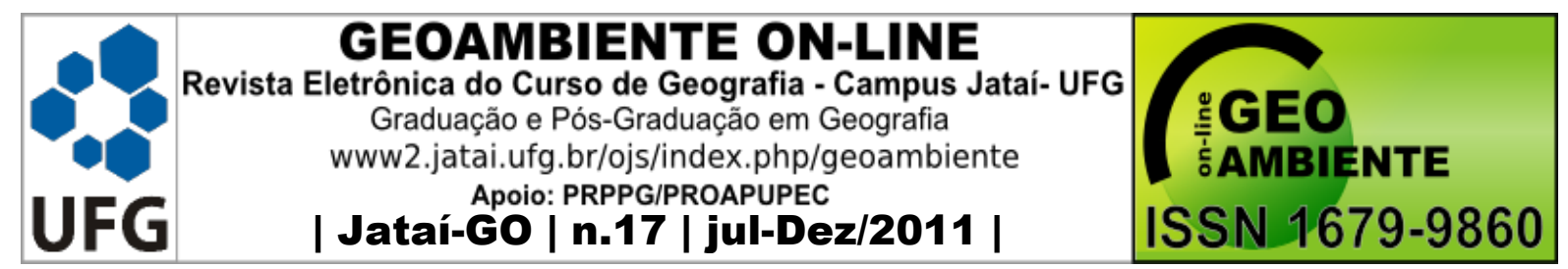

situação de alta vulnerabilidade, porém, sem risco de contaminação se não existir carga poluidora significativa, ou vice-versa. A carga poluidora pode ser controlada ou modificada; mas o mesmo não ocorre com a vulnerabilidade natural, propriedade intrínseca do aqüífero (FOSTER; HIRATA, 1993).

Hassuda (1999) defende a importância de se correlacionar ao estudo da vulnerabilidade natural dos aqüíferos, as atividades exercidas em superfície, pois, embora o meio natural apresente uma estrutura natural frágil, é o tipo, intensidade, forma e tempo de disposição das atividades que determinam a real situação do risco a que os aqüíferos estão submetidos. Em muitos casos, a forma de ocupação do solo, pode modificar a qualidade dos recursos hídricos, pondo em risco sua conservação para o uso das atuais e futuras gerações.

Para Xavier da Silva e Carvalho Filho (1993), a poluição é um processo paulatino e sub-reptício. Entretanto, a previsão da possível ocorrência dessas áreas críticas pode ser apoiada no geoprocessamento, através do confronto entre mapas, para a identificação de entidades poluidoras (pela localização e distribuição geográfica dos agentes poluidores) e, conseqüentemente, criação de normas eliminadoras e/ou mitigadoras da ação poluente. Riscos de poluição podem ser cotejados contra o potencial de recursos hídricos de uma área, como no caso, os aquíferos. Nesses casos, de riscos de poluição, o apoio à decisão quanto à criação de normas de manejo ambiental é praticamente imediato, com base na definição de áreas críticas, onde a poluição possa incidir sobre locais a serem protegidos.

Assim, entende-se por risco de contaminação, quando são desenvolvidas atividades potencialmente contaminantes sobre áreas vulneráveis à contaminação das águas subterrâneas. Dessa forma, o trabalho tem como objetivo, realizar um levantamento das atividades potencialmente contaminantes e, apoiado no geoprocessamento, confrontá-las com a vulnerabilidade natural, no Campus da UFSM - RS.

\section{Atividades potencialmente contaminantes}

Entende-se por atividades geradoras de poluição e/ou que ofereçam risco de poluição, toda e qualquer atividade socioeconômica que se desenvolva sobre a superfície terrestre e gere resíduos e/ou efluentes (líquidos, sólidos ou gasosos) que não recebem tratamento adequado antes de serem re-introduzidos no ambiente natural, assim como, o uso abusivo de defensivos agrícolas e nitratos, poços construídos e abandonados, que podem ser mal utilizados, e causar, nesse caso, poluição de forma direta. 


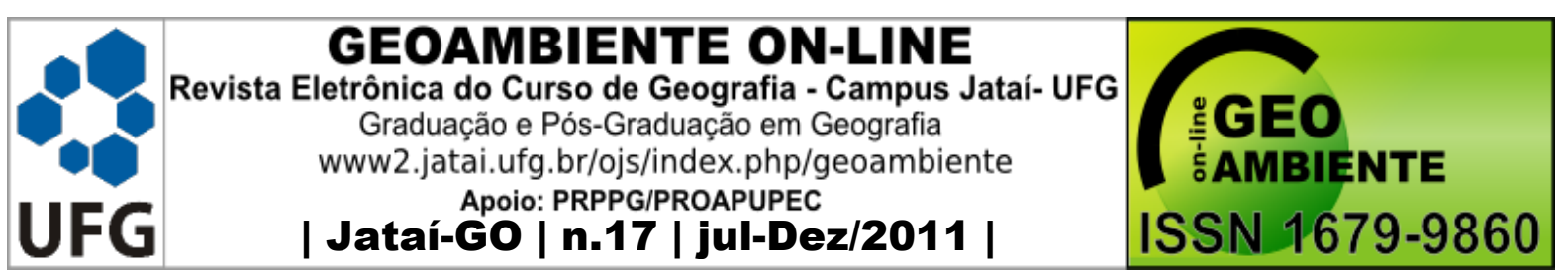

As possíveis fontes de contaminação da água subterrânea podem ser classificadas, conforme sua forma de ocorrência em pontuais e difusas. Mook (2002) cita que as fontes mais comuns de contaminação das águas subterrâneas são: áreas urbanas; atividades agrícolas e industriais; águas residuais despejadas nos rios e nos drenos; depósitos de resíduos; água salgada contaminada, atraída pela exploração intensiva dos recursos de água subterrânea na região litorânea (intrusão salina).

As áreas agrícolas são um exemplo típico de fonte de contaminação difusa, devido às práticas inadequadas de manejo do solo que podem causar uma séria poluição nas águas subterrâneas, com taxas elevadas de nitratos no uso do cultivo da soja, milho, arroz, fumo, etc. Defensivos agrícolas, quando aplicados demasiadamente, são contaminantes nocivos na alteração da qualidade da água subterrânea e, normalmente, não avaliados em seu monitoramento.

Em áreas urbanas, a principal preocupação é a poluição pontual, ocorrida por carga poluidora em zonas residenciais sem esgotamento sanitário, com tanques sépticos e fossas negras; tal carga inclui nutrientes (nitrogênio e enxofre), sais (cloreto), bactérias, vírus e compostos orgânicos sintéticos. No caso da rede coletora de esgoto que lança os efluentes de uma cidade ou parte dela, em apenas um ponto de um canal fluvial, ela pode ser considerada como pontual concentrada. Foster et al. (2003) comentam também que em áreas de concentração industrial, devido à extrema diversidade de atividades, de processos de fabricação e de práticas de disposição de efluentes, há maior dificuldade em ser estimada a carga poluidora.

Figura 1 - Processos comuns de contaminação d'água subterrânea.

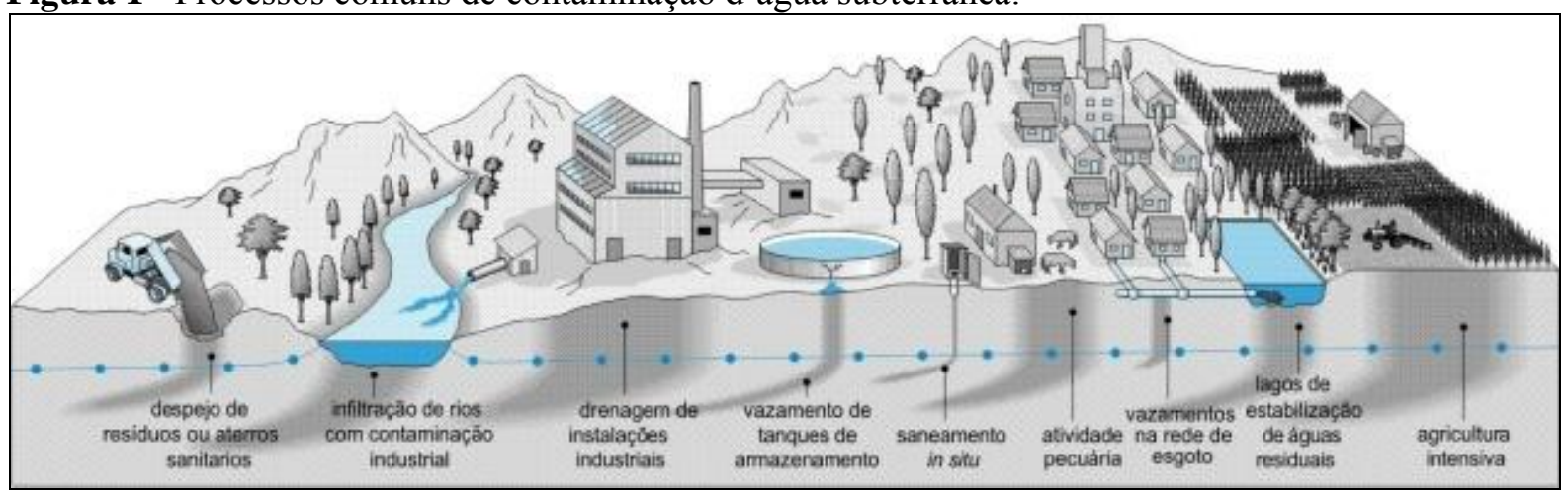

Adaptado de: Foster et al. (2003).

Segundo Hirata (2000, p. 437), as atividades mais importantes no contexto latinoamericano são "os sistemas de saneamento in situ, ou aqueles que infiltram os efluentes 


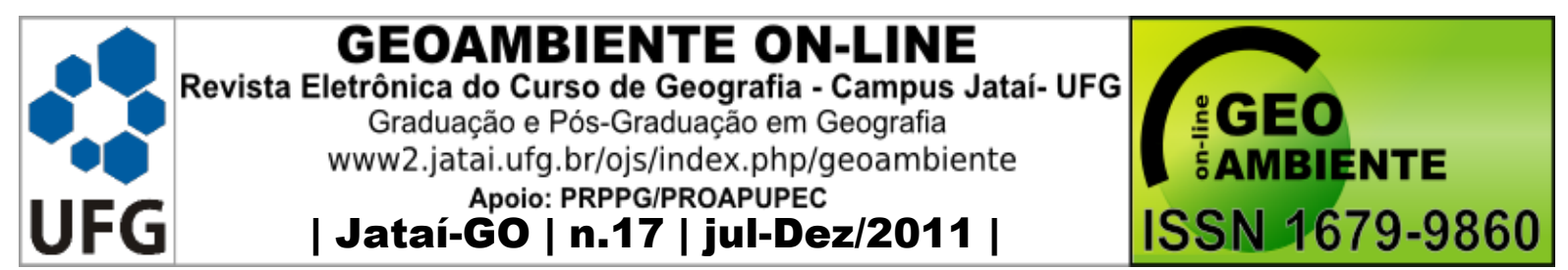

diretamente no solo, como deposição incorreta de resíduos sólidos, vazamento de postos de combustíveis, entre outras". No caso de áreas urbanas sem rede de coleta de esgoto, Hirata (2000), estabeleceu também, critérios para classificação das cargas potenciais poluidoras de fontes dispersas, esgoto in natura, em três faixas conforme a quantidade de nitrato gerado pela população por ano $\left(\mathrm{Kg} \mathrm{N}^{-} \mathrm{NO}_{3}{ }^{-} / \mathrm{ano}\right)$ : reduzida para populações urbanas inferiores a 20.000 habitantes; moderada para população entre 20.000 a 50.000 e elevada para populações urbanas acima de 50.000 .

Geralmente, é possível estimar o volume de efluente a partir da quantidade de água utilizada, mas é difícil estabelecer a fração infiltrada no subsolo. Resíduos sólidos, depositados em lixões ou dispostos em aterros sanitários, podem ter seus volumes de lixiviados estimados com certa segurança; em muitos casos, porém, não há informação confiável sobre a sua composição. Em todos eles, torna-se necessário identificar cada fonte e analisá-las individualmente por monitoramento (SILVERIO DA SILVA et al, 2005).

\section{Caracterização da área em estudo}

O Campus da UFSM abrange a Cidade Universitária Prof. José Mariano da Rocha Filho, situada no Bairro Camobi, município de Santa Maria, Estado do Rio Grande do Sul (RS), no qual é realizada a maior parte das suas atividades acadêmicas e administrativas. Situa-se aproximadamente, a $9 \mathrm{~km}$ do centro de Santa Maria e a $290 \mathrm{~km}$ de Porto Alegre. Possui uma área total de 1.129,4598 hectares, dividida em área velha (528,6649 ha), integrada hoje ao perímetro urbano de Santa Maria e a área nova que está atualmente inserida na zona rural do município, a qual foi adquirida em 1988 (600,7949 ha). Estima-se, por dados da Prefeitura da Cidade Universitária, que no ano de 2008 circularam diariamente pelo Campus cerca de 20.000 pessoas.

Figura 2: Localização da área em estudo. 


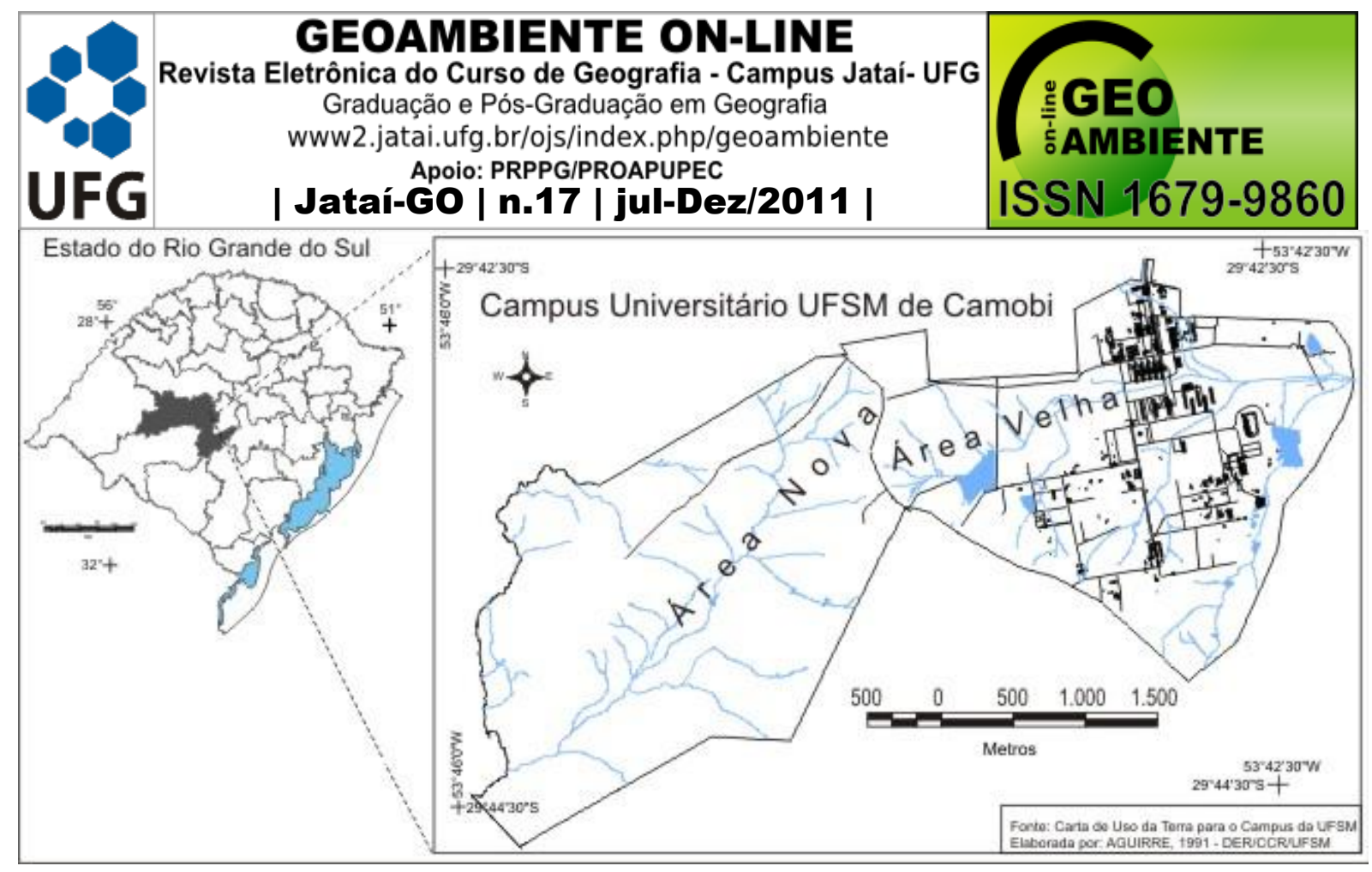

Para Nimer (1990), o regime climático da área, onde se enquadra o município de Santa Maria, é caracterizado por precipitações regulares com índices pluviométricos anuais entre 1.500 a $1.750 \mathrm{~mm}$ com chuvas ocasionadas pela passagem de frentes frias, intensificadas pelo efeito orográfico do Rebordo do Planalto e, eventualmente, pela formação de frentes quentes. Esses índices são importantes na estimativa da recarga direta pela infiltração das águas meteóricas no sub-solo. Nesse sentido, Hausman (1995) estimou para a área uma taxa de infiltração entre 3 e $6 \%$ da precipitação média anual.

No Campus UFSM já foram perfurados aproximadamente 50 poços. Destes, 24 poços estão em atividade e capturam água, principalmente, da formação geológica Santa Maria, que compõem, no local, a borda do Sistema Aqüífero Guarani. De acordo com Rocha (1997), o termo Aqüífero Guarani é a denominação formal dada ao reservatório transfronteiriço de água subterrânea doce, formado pelos sedimentos flúvio-lacustres do período Triássico (245-208 milhões de anos) e por sedimentos eólicos desérticos do período Jurássico (208-144 milhões de anos). Tem extensão total aproximadamente de 1,2 milhões de $\mathrm{Km}^{2}$, sendo 840 mil $\mathrm{Km}^{2}$ no Brasil, 225,5 mil Km² na Argentina, 71,7 mil Km² no Paraguai e 58,0 mil Km² no Uruguai.

Em algumas épocas do ano, os poços não suprem a demanda requerida para atender às mais diversas finalidades desenvolvidas no Campus. O Hospital Universitário (HUSM), por ser público e referência em casos de alta complexidade, atende 45 municípios da região Centro-oeste do Estado do Rio Grande do Sul e, por isso, necessita de água em quantidade e qualidade, conforme exige a Portaria do MS nº 518/2004. Com a expansão do Campus, e com a abertura de novos cursos, a tendência é de aumento significativo do consumo. 


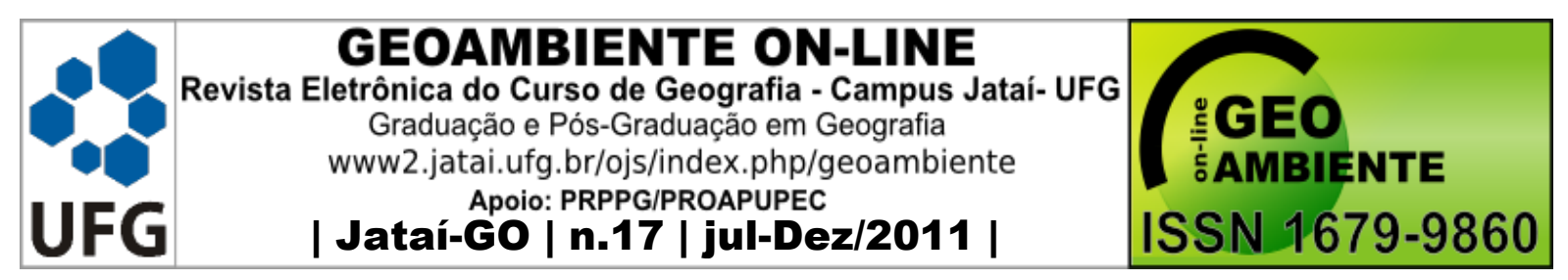

\section{Materiais e métodos}

Para a elaboração do Cartograma da Superfície Potenciométrica, que é obtido pelo conjunto de níveis potenciométricos (formados pela cota altimétrica do nível d’água dos poços de uma determinada área), foram utilizados os dados referentes à cota altimétrica da "boca do poço", obtidos a partir dos marcos geodésicos implantados pelo projeto SIG-UFSM, com o uso de estação total, e do Nível Estático dos poços (nível d'água em estado de repouso). Tal procedimento possibilita a inferência do provável fluxo subterrâneo d'àgua e, conseqüentemente, a dispersão de possíveis contaminantes.

Do valor da cota altimétrica da boca do poço, foi descontada a distância até o Nível Estático (NE) da água subterrânea, obtendo-se assim, a cota altimétrica do nível da água (nível potenciométrico). Os dados referentes ao $\mathrm{NE}$ foram obtidos por testes de bombeamento, realizados pela empresa Hidrobrasil Perfurações. Essa relação possibilita uma estimativa da altura ortométrica da coluna d'água em relação ao datum vertical, nível do mar no porto de Imbituba (Estado de Santa Catarina). Os níveis potenciométricos foram então espacializados com o uso do aplicativo Surfer 8.0. Para a escolha do método de interpolação matemática, testaram-se os 4 métodos tidos como principais por Silva (2003): Inverso do quadrado da distância, Krigagem, Curvatura mínima e Triangulação de Delaunay.

A análise ambiental por geoprocessamento baseia-se metodologicamente em Xavier da Silva (2001). Para a identificação das atividades potencialmente contaminantes, primeiramente, foi buscado as informações necessárias junto a Comissão Ambiental da UFSM e a Prefeitura da Cidade Universitária. Essa última, forneceu uma planta de fossas e de redes de esgoto do ano de 2008. De posse da mesma, foram realizados levantamentos de campo para verificar as atividades potencialmente contaminantes desenvolvidas no Campus da UFSM e, classificá-las, baseado em Hirata (2000), entre pontuais, lineares e difusas.

Para a estimativa de suas possíveis áreas de influência, no aplicativo ArcMap 9.2, foram gerados buffers, técnica utilizada para representar distâncias conforme o tipo de potencial poluidor, ou seja, quanto maior é o seu potencial poluidor, maior a possível área de abrangência, atribuída a essa atividade. O mapa então gerado, no aplicativo ArcMap 9.2, foi exportado com resolução espacial de 2 metros, o que corresponde ao tamanho do pixel no terreno. Essa resolução foi utilizada por ser a mesma do Mapa da Vulnerabilidade Natural, ver figura 4, pois, para a realização da combinação dos mapas em ambiente matricial, a resolução, 


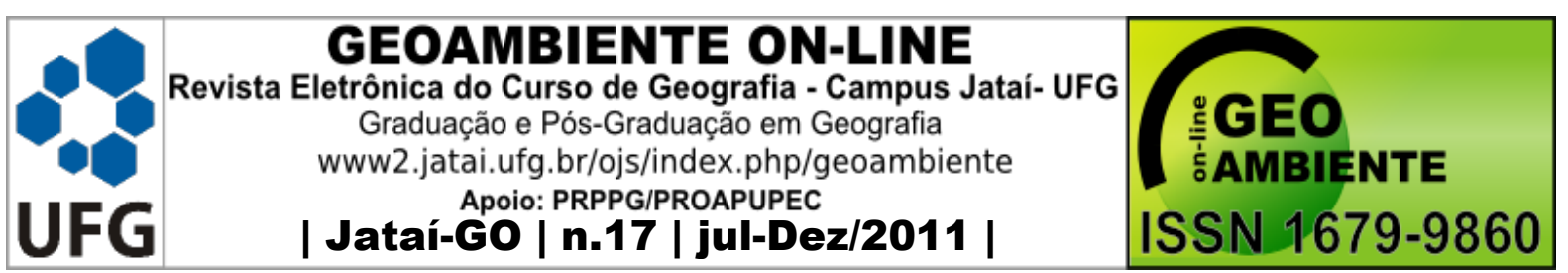

além do número de linhas e de colunas deve ser igualitária. Para o cálculo da resolução espacial, utilizou-se o aplicativo Georref, desenvolvido pelo Lageop/UFRJ (Laboratório de Geoprocessamento da Universidade Federal do Rio de Janeiro).

No aplicativo SAGA 2007 (Sistema de Análise Geoambiental), foi realizada a combinação entre o Mapa da Vulnerabilidade Natural, elaborado por Marion (2009) versus o levantamento das atividades potencialmente contaminantes. Para a realização desse levantamento, foi vistoriado todo o Campus e demarcados os pontos com atividades potencialmente contaminantes com o uso de receptor GPS (Global Position System). Esse procedimento possibilita verificar in loco a ocorrência de atividades potencialmente contaminantes, sobre áreas de alta vulnerabilidade, o que caracteriza risco potencial de contaminação as águas subterrâneas. Nos aplicativos computacionais CorelDRAW e Corel Photo-Paint, foi realizado o acabamento final do mapa.

Abaixo segue o organograma que gerou o mapa utilizado para verificação dos conflitos.

Figura 3: Organograma das informações.

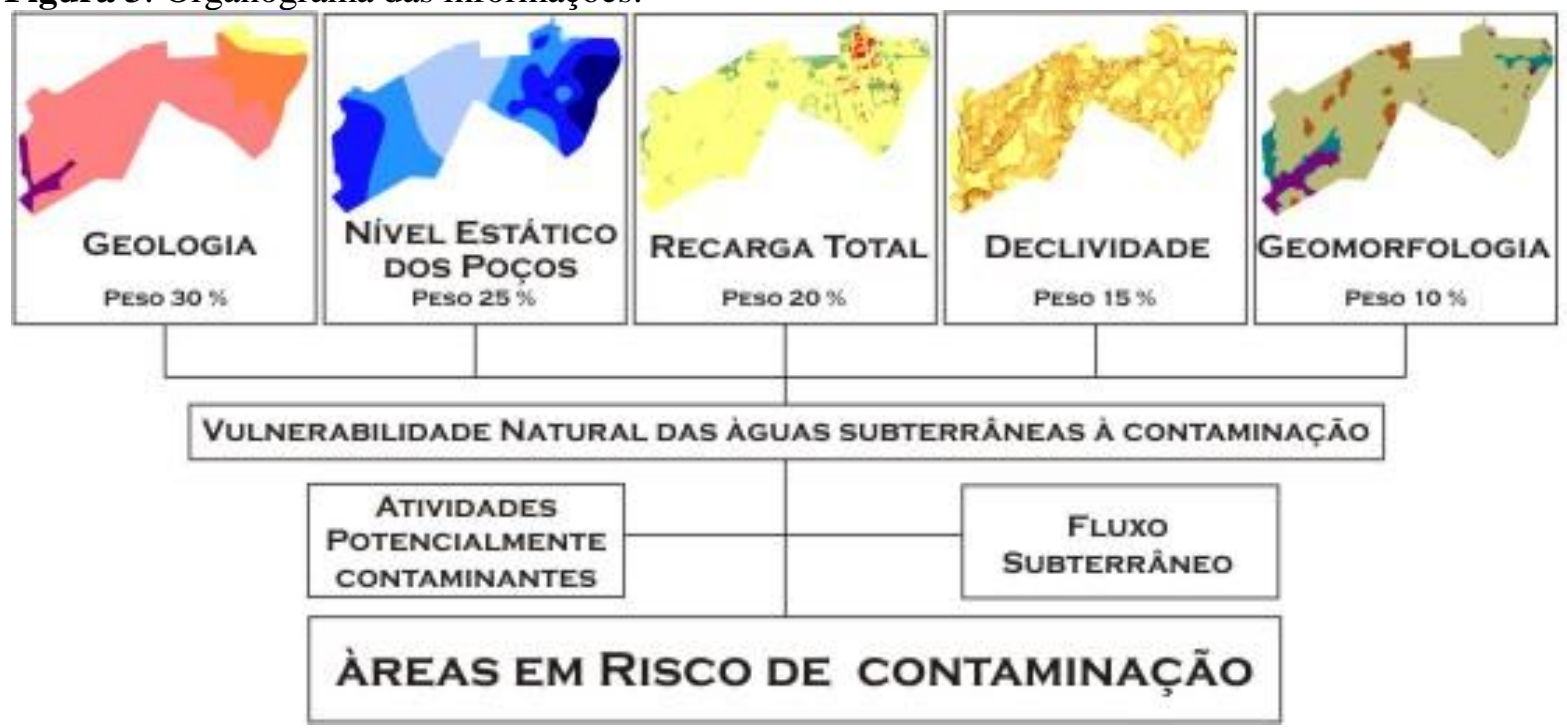

Figura 4: Mapa da Vulnerabilidade Natural utilizado no confronto com as atividades potencialmente contaminantes. 


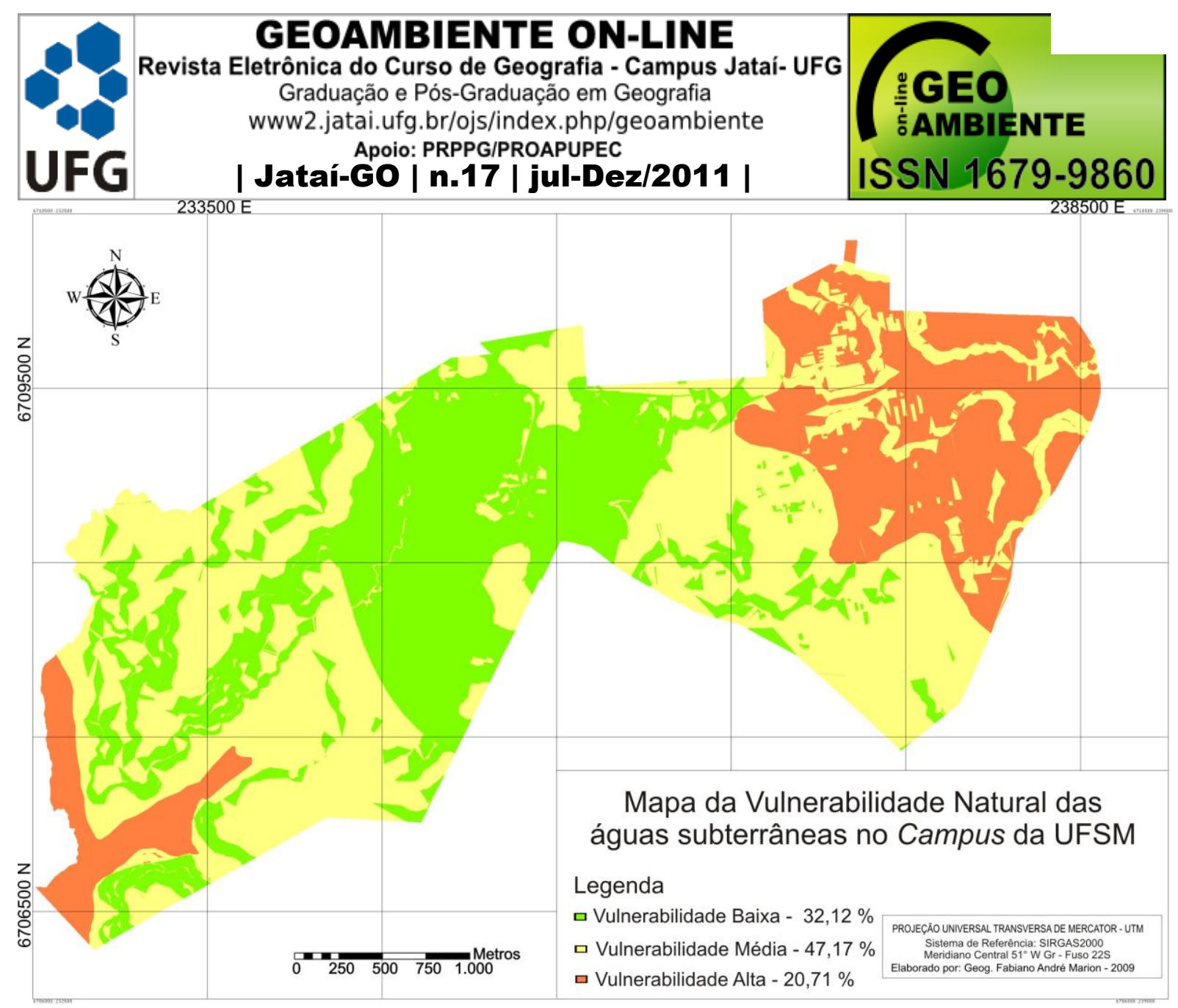

Fonte: Marion, 2009.

\section{Apresentação e Discussão dos Resultados}

A profundidade do lençol freático variou de 15,35 a 39,38 m. Já a superfície potenciométrica, que indica o provável fluxo da água subterrânea e, conseqüentemente, a provável dispersão dos contaminantes, variou entre 46,78 a $85,70 \mathrm{~m}$, indicando um desnível da carga hidráulica de 39 metros na área em estudo. O desnível representa o fluxo subterrâneo predominante no sentido de sul/sudoeste para norte/nordeste da área em estudo, em direção ao Bairro Camobi. A direção do fluxo é a mesma das camadas geológicas, que se encontram mergulhadas em direção norte, para o centro da Bacia Sedimentar do Paraná.

A figura 5 apresenta o cartograma da superfície potenciométrica. A Krigagem ordinária foi o método de interpolação espacial que mais se aproximou da realidade da área. No cartograma, estão também representados os poços utilizados na pesquisa, e suas respectivas siglas. As setas representam a direção do fluxo e a sua intensidade, conforme o seu tamanho.

Figura 5: Cartograma da Superfície Potenciométrica e a localização dos poços estudados. 


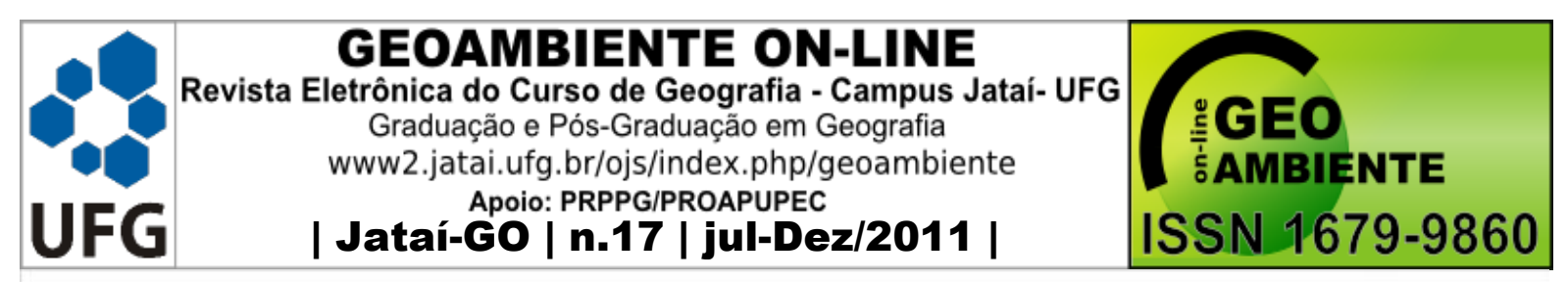

\section{Superfície Potenciométrica do Campus da UFSM}

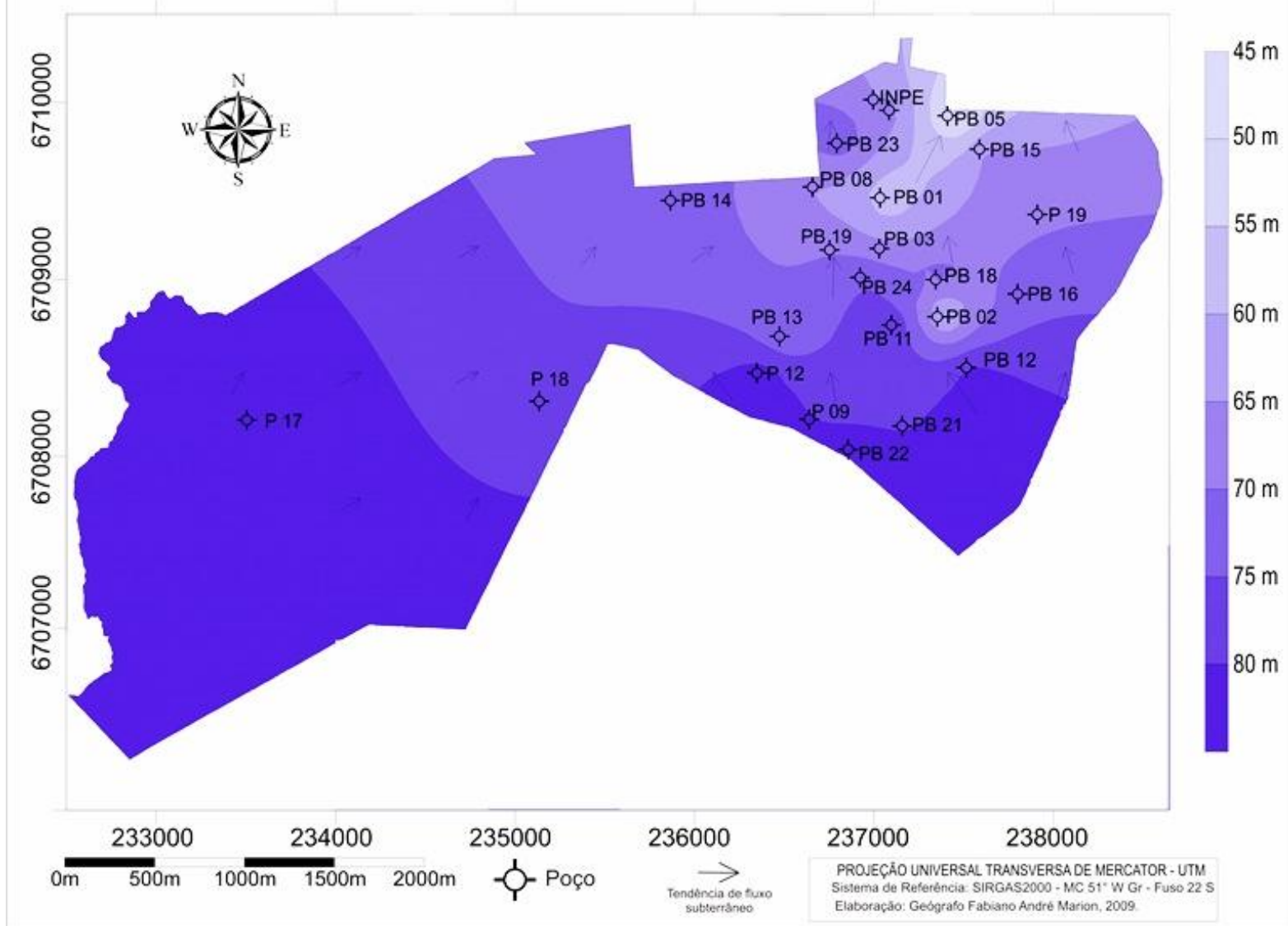

Em estudo realizado apenas na área velha do Campus Universitário da UFSM, Moreira (2005) também constatou esse mesmo sentido para o fluxo subterrâneo. O cartograma da superfície potenciométrica pode ser utilizado no planejamento de futuras áreas de expansão e alocação de atividades potencialmente contaminantes, pois, através dele, podese inferir uma possível dispersão dos mesmos, caso ela ocorra.

O sistema de Esgotamento Sanitário da UFSM é subdividido em duas grandes redes coletoras principais. Tais redes atendem a grande parte da Cidade Universitária e apenas alguns prédios isolados não estão ligados a ela. Possui suas redes individuais e conta com estações de tratamento do tipo fossa e filtro anaeróbio e/ou sumidouro. As águas residuais desse esgotamento são drenadas por uma rede de esgoto principal até outra fossa-filtro e, após, lançadas na drenagem fluvial.

$\mathrm{Na}$ entrada principal da UFSM, verifica-se uma vala com um córrego que recebe esgotos não tratados, os quais adentram pela Avenida Roraima, oriundos do Bairro Camobi. Esses esgotos, juntam-se com os da Universidade e, o córrego Mariano da Rocha que os 


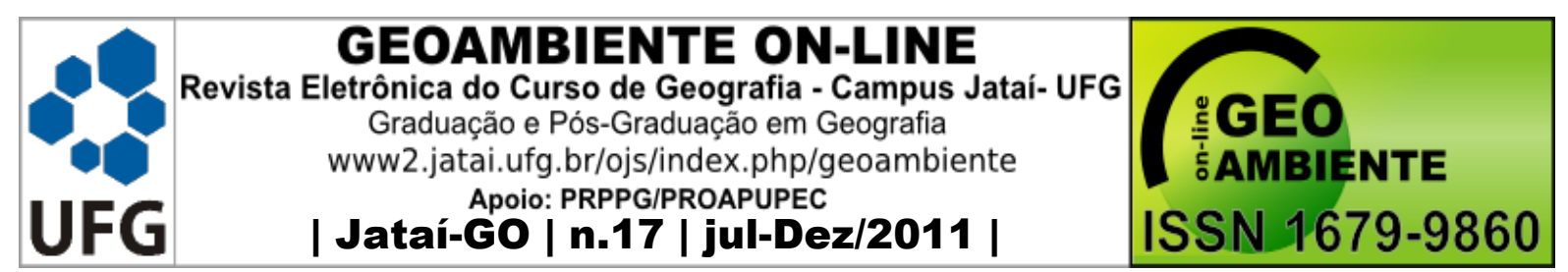

recebe, percorre uma área de alta vulnerabilidade natural à contaminação, acabando por desaguar no arroio Lagoão do Ouro, constituindo-se numa possível forma de contaminação.

D’Ávila (2009), ao analisar e comparar a qualidade d'água desse córrego, com a legislação federal de recursos hídricos, constatou que a qualidade permanece fora dos padrões estabelecidos nos 2 pontos analisados: entrada e saída do Campus. Embora esses valores sejam decrescentes ao longo do curso d'água, devido à autodepuração, boa parte desses contaminantes pode infiltrar, uma vez que a litologia local, Formação Santa Maria - Membro Passo das Tropas, é altamente vulnerável à contaminação. Portanto, o despejo de águas residuais é inadequado, pois é uma área altamente vulnerável, o córrego já chega poluído ao Campus e com sua capacidade de auto-depuração esgotada.

A seguir, a tabela 1 apresenta as atividades potencialmente contaminantes identificadas em trabalho de campo no Campus da UFSM, a forma de dispersão e sua provável abrangência.

Tabela 1 - Atividades potencialmente contaminantes identificadas no Campus da UFSM e sua possível abrangência.

\begin{tabular}{|c|c|c|}
\hline Atividades & Forma de dispersão & Abrangência (buffer) \\
\hline Posto de Combustíveis e lava-jato & Pontual & $120 \mathrm{~m}$ \\
\hline Lançamento sanitário principal & Pontual & $80 \mathrm{~m}$ \\
\hline Manejo de agroquímicos & Pontual & $80 \mathrm{~m}$ \\
\hline Rede esgoto principal & Linear & $60 \mathrm{~m}$ \\
\hline Fossa-filtro & Pontual & $60 \mathrm{~m}$ \\
\hline Hospital Universitário - HUSM & Pontual & $50 \mathrm{~m}$ \\
\hline Hospital de Clínica Veterinária - HCV & Pontual & $50 \mathrm{~m}$ \\
\hline Laboratórios Depto de Química & Pontual & $50 \mathrm{~m}$ \\
\hline Restaurante Universitário & Pontual & $50 \mathrm{~m}$ \\
\hline Sanga poluída & Linear & $50 \mathrm{~m}$ \\
\hline Lançamento sanitário secundário & Pontual & $50 \mathrm{~m}$ \\
\hline Rede esgoto secundária & Linear & $50 \mathrm{~m}$ \\
\hline Agroindústria & Pontual & $30 \mathrm{~m}$ \\
\hline \multirow{6}{*}{ 胥 } & Difusa & $200 \mathrm{~m}$ \\
\hline & Pontual & $200 \mathrm{~m}$ \\
\hline & Pontua/Difusa & $80 \mathrm{~m}$ \\
\hline & Pontual & $80 \mathrm{~m}$ \\
\hline & Pontual & $50 \mathrm{~m}$ \\
\hline & Pontual & $30 \mathrm{~m}$ \\
\hline
\end{tabular}

Fonte: Trabalho de Campo, 2009.

A rede de esgoto, por possibilitar infiltração de possíveis contaminantes, caso haja vazamentos, é considerada como atividade potencialmente contaminante linear, e as fossas, juntamente com os locais de lançamento sanitário, como de poluição pontual. Entretanto, a 


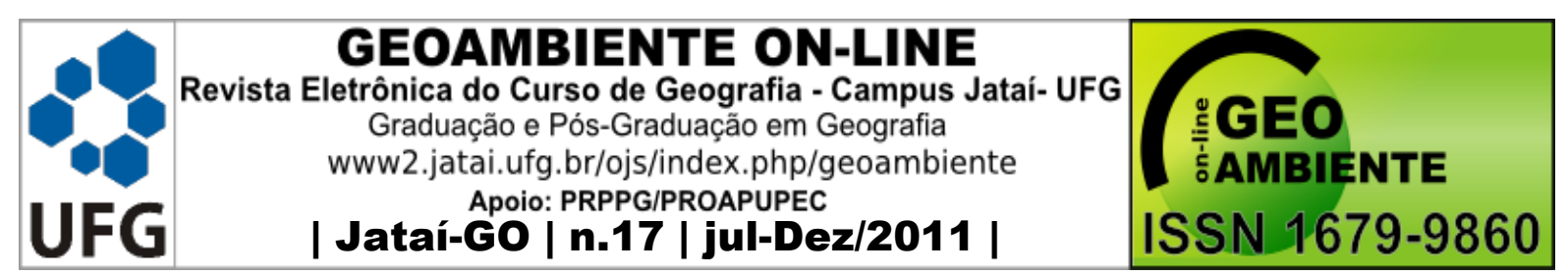

planta cedida pela Prefeitura da Cidade Universitária está incompleta, pois muitos prédios aparecem sem ligação à rede de esgoto e sem fossa, o que dificulta uma análise completa desse caso. De acordo com dados do Setor de Manutenção, em janeiro de 2009, existiam 75 fossas no Campus. Dessas, 46 recebem esgoto cloacal, 18 recebem esgoto cloacal e de laboratório, 10 recebem somente esgoto de laboratório e uma recebe resíduos de cozinha.

As fontes de contaminação como os postos de combustíveis, também merecem muita atenção, pois utilizam produtos não biodegradáveis e, considerando-se o tempo de execução, a idade dos tanques e o seu contato com o solo, poluentes podem atingir os recursos hídricos subterrâneos, dependendo do grau de vulnerabilidade da área que, no caso do local onde se encontra o posto de combustíveis, é de alta vulnerabilidade. Além do mais, o posto de combustíveis, localizado dentro do Campus da UFSM, possui lava-jato, o que aumenta o potencial poluidor. Dessa forma, por exemplo, caso houver vazamento de algum tanque de armazenamento, ocorrerá risco eminente de contaminação às águas subterrâneas.

Pelo fato de a Universidade trabalhar com pesquisas nas mais diversas áreas do conhecimento, muitas delas utilizam produtos altamente tóxicos. Citam-se como exemplo, os laboratórios da área química e de manejo e experimentação de agroquímicos. $\mathrm{Na}$ área de experimentos agrícolas do Departamento de Solos, é realizada a lavagem de utensílios agrícolas e o manuseio de agroquímicos, em área de alta vulnerabilidade, e não há poço de monitoramento instalado.

Com relação às atividades de produção animal, nenhuma delas localiza-se em áreas de alta vulnerabilidade e, segundo os responsáveis pelos setores, o manejo dos dejetos é realizado de maneira adequada. Entretanto, no setor de suinocultura, as lagoas de decantação, que recebem os dejetos suínos, não são impermeabilizadas, e a água residual é lançada no ambiente. Para minimizar esse problema, existe um projeto de construção de um biodigestor, elaborado pelo Professor do Setor de Suinocultura do Departamento de Zootecnia da UFSM, Gerson Garcia. De acordo com o mesmo, o material produzido por sistemas de criação de suínos é rico em nitrogênio, fósforo e potássio. Desses, o nitrogênio é o elemento que mais oferece risco de contaminação à água subterrânea quando lixiviado, pois, através do processo de nitrificação, se mineralizarem em nitratos e nitritos. $\mathrm{O}$ biodigestor, pelo uso de filtros orgânicos, proporcionaria um sistema de reuso da água residuária proveniente da suinocultura. 


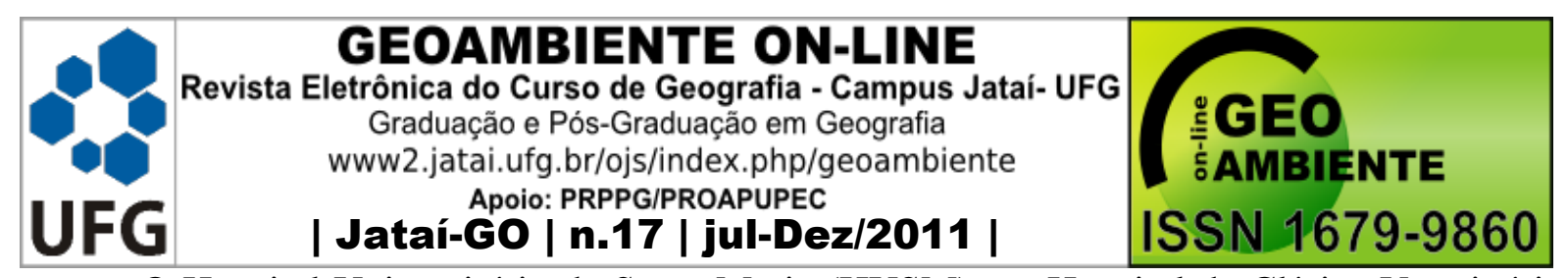

O Hospital Universitário de Santa Maria (HUSM) e o Hospital de Clínica Veterinária (HCV), são públicos e referência regional e, assim como os demais hospitais, são atividades potencialmente contaminadoras, uma vez que realizam cirurgias e tratam doenças infectocontagiosas. Com uma oferta de 289 leitos divididos em 22 clínicas, incluindo um prontosocorro, o HUSM é referência em alta complexidade para toda a região centro-oeste do Rio Grande do Sul. Por realizar tratamento por hemodiálise, o mesmo é obrigado a utilizar água de excelente qualidade, de acordo com as normas da Portaria do MS n 518/2004, o que reforça a necessidade de conservação da qualidade das águas subterrâneas na UFSM.

Os resíduos sólidos, quando lançados inadequadamente em superfície, assim como os cemitérios, representam uma significante fonte de contaminação para as águas superficiais e subterrâneas. Por isso, deve-se selecionar de modo mais adequado possível suas locações, para que o meio ambiente não seja mais gravemente atingido, mais especificamente os recursos hídricos superficiais e subterrâneos. No caso da UFSM, não existe cemitério, o lixo normal é recolhido pela Prefeitura do município de Santa Maria e o lixo produzido pelos laboratórios, pelo HUSM e pelo $\mathrm{HCV}$, é recolhido por empresa terceirizada, incluindo resíduos e perfuro-cortantes, que têm como destino um aterro sanitário, instalado fora do Campus da UFSM.

Pela integração do Mapa de Vulnerabilidade natural (figura 4), com as zonas em que pode ocorrer poluição, identificou-se, por geoprocessamento, uma área de 42 ha de alta vulnerabilidade com provável área de influência de atividades potencialmente contaminantes. Essa área apresenta a cor vermelha no Mapa de risco à contaminação das águas subterrâneas (figura 6) e requer atenção dobrada, uma vez que, se houver infiltração proveniente de alguma atividade potencialmente contaminante, poderá ocorrer poluição das águas subterrâneas nesse setor do Campus da UFSM. As principais atividades potencialmente contaminantes encontradas nessa área, são o posto de combustíveis, o manejo de agrotóxicos, o lançamento sanitário de águas residuais de fossas e a sanga poluída que percorre o setor nordeste do Campus.

Com relação à área de vulnerabilidade média, a provável área de influência de atividades potencialmente contaminantes abrange 43 ha. As principais atividades potencialmente contaminantes que ocorrem na área de média vulnerabilidade é o HUSM, o $\mathrm{HCV}$, o Restaurante Universitário, a rede de esgoto, as fossas e as atividades de produção animal. Já nas áreas de baixa vulnerabilidade, que é a área naturalmente mais protegida, são 


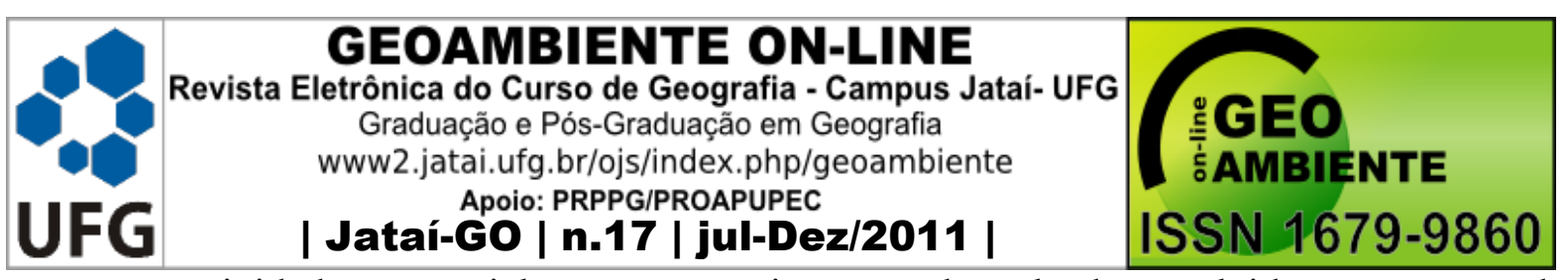

poucas as atividades potencialmente contaminantes sobre ela desenvolvidas, apenas as de produção animal.

Figura 6: Mapa dos conflitos gerado pelo confronto entre a Vulnerabilidade Natural das águas subterrâneas com a área de influência das atividades potencialmente contaminantes.

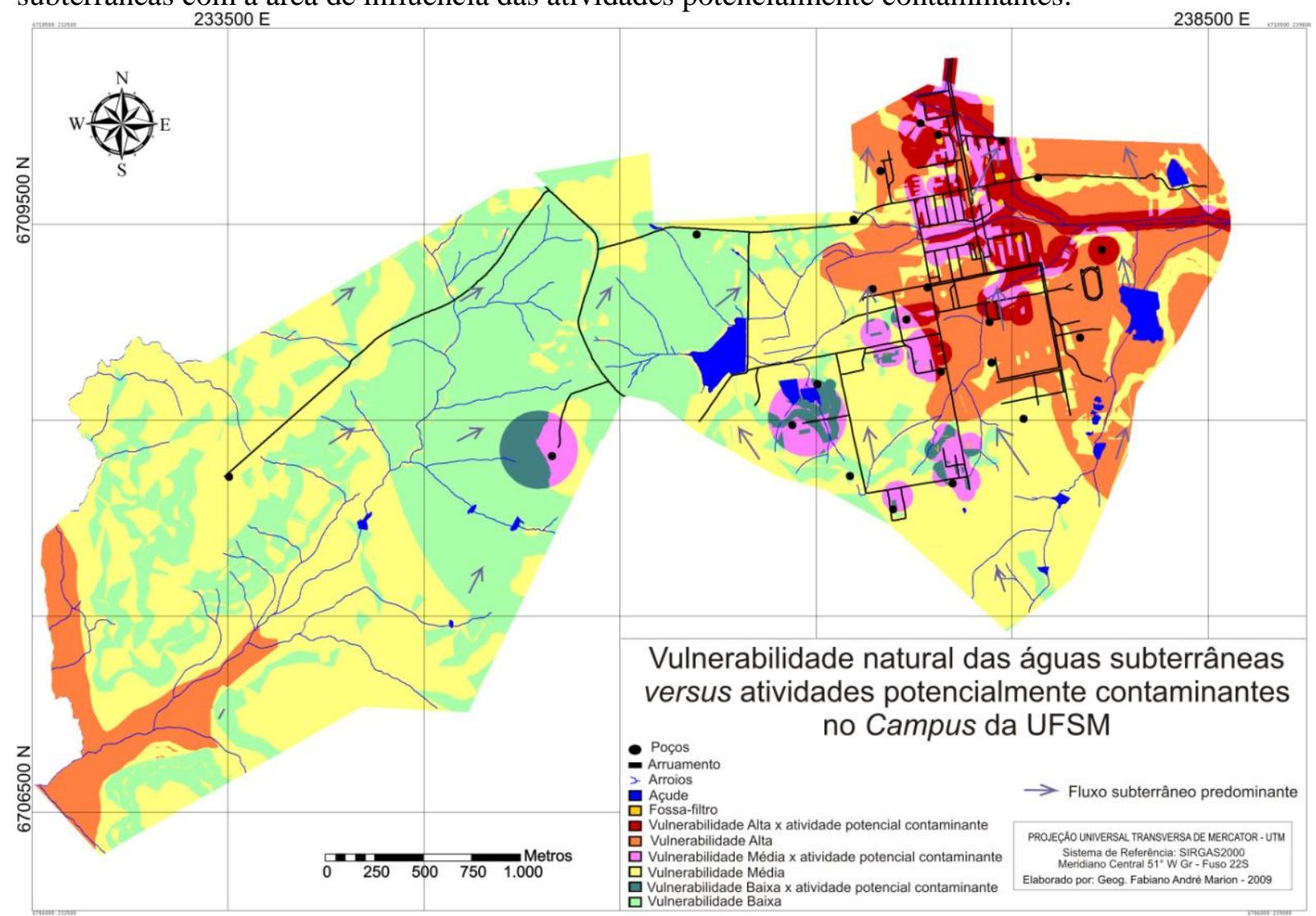

Figura 6: Mapa dos conflitos gerado pelo confronto entre a Vulnerabilidade Natural das águas subterrâneas com a área de influência das atividades potencialmente contaminantes.

Por isso, é recomendável que as áreas de baixa vulnerabilidade, sejam utilizadas para a locação de futuras atividades potencialmente contaminantes, como por exemplo, para a expansão da área urbanizada do Campus. É também recomendada, juntamente com demais estudos, para a construção de um novo HUSM, uma vez que o mesmo encontra-se próximo à cabeceira de pouso da Base Aérea de Santa Maria e sobre uma área de média e alta vulnerabilidade à contaminação.

Frente aos resultados aqui encontrados, principalmente no que se refere aos 85 ha com abrangência de atividades inadequadas que põem em risco a qualidade da água subterrânea, faz-se extremamente necessária a construção de uma usina de tratamento de esgotos na Universidade, uma vez que a maioria das atividades potencialmente contaminantes 


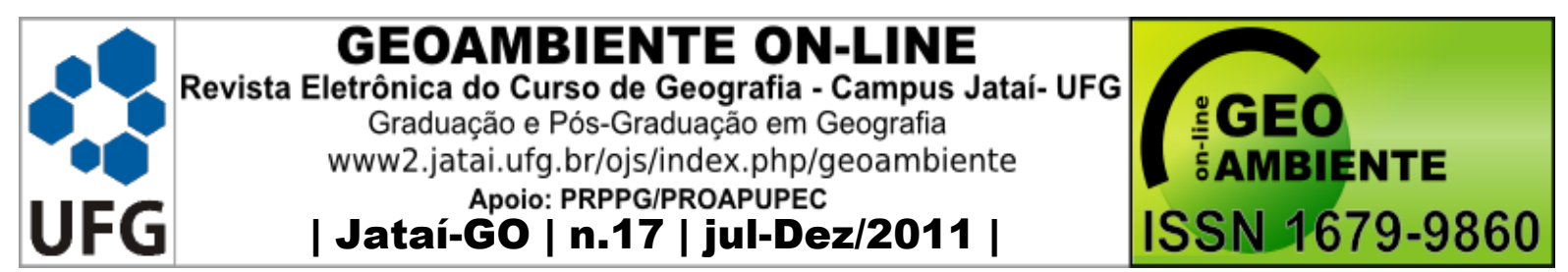

desenvolvidas no Campus Universitário, inclusive o lançamento sanitário de águas residuais das fossas-filtro, ocorrem em área de alta vulnerabilidade à contaminação das águas subterrâneas. A usina de tratamento de esgotos poderia atender também ao Bairro Camobi, uma vez que, uma parte dos esgotos gerados por ele adentra o Campus e percorrem uma área de alta vulnerabilidade à contaminação dos aqüíferos.

Além de beneficiar a Universidade no ponto de vista ambiental, a usina poderá reduzir os custos que a UFSM tem com a destinação do lixo hospitalar e do lixo tóxico gerado nos laboratórios. Através de estudos aprofundados, poderia ser verificada a possibilidade de tratamento de alguns deles nessa usina, o que reduziria os elevados custos de transporte e destinação desse material, realizado atualmente por empresa terceirizada.

\section{Considerações finais}

Uma melhor caracterização do risco de poluição das águas subterrâneas consiste, na associação e interação da vulnerabilidade natural do aquífero com as atividades desenvolvidas no solo ou em sub-superfície. Por isso, é extremamente importante, em estudos de vulnerabilidade de aqüíferos, realizar levantamentos das atividades potencialmente contaminantes, uma vez que a carga poluidora pode ser controlada ou modificada; mas o mesmo não ocorre com a vulnerabilidade natural, propriedade intrínseca do aqüífero.

Nesse sentido, as geotecnologias e, em especial o geoprocessamento, mostram-se extremamente importantes, pois, além de possibilitar a identificação das áreas vulneráveis pela integração de variáveis ambientais, os mesmos servem para realizar a interação da vulnerabilidade natural com as áreas de influência das atividades potencialmente contaminantes.

O fato de o setor urbanizado do Campus estar sobre áreas de alta e média vulnerabilidade, com a conseqüente maior geração de riscos de poluição, conforme resultados apresentados, demonstra a necessidade imediata de construção de uma usina de tratamento de esgotos no Campus e uma possível realocação de algumas atividades que oferecem risco de contaminação, uma vez que a maioria das atividades potencialmente contaminantes estão inseridas em área de alta vulnerabilidade.

Sugere-se também, que as áreas de Reserva Legal, que virem a ser criadas no Campus Universitário da UFSM, sejam locadas sobre alguma área de alta vulnerabilidade à contaminação dos aquiíferos, deixando para as áreas de baixa vulnerabilidade, a locação das 


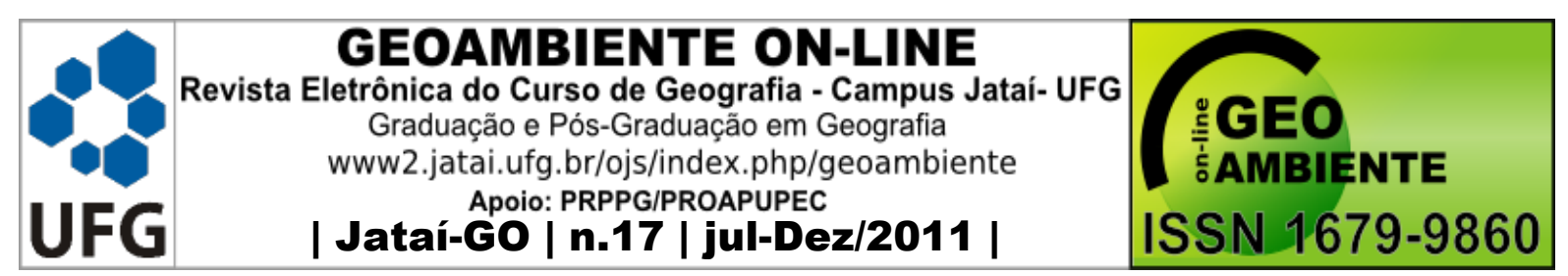

atividades urbanas e/ou que ofereçam risco de contaminação. Tal procedimento também influirá na recarga direta por infiltração da água das chuvas, somando-se as reservas renováveis anuais.

Recomenda-se, também, ampliar o estudo para as áreas adjacentes, a fim de confirmar as tendências de fluxos subterrâneos verificadas nesse trabalho e as condições de recarga natural, para a sua proteção e manejo sustentável, em especial, o Sistema Aqüífero Guarani. Nesse sentido, é fundamental também a realização de testes de qualidade da água, periodicamente, para se avaliar a possível ocorrência de contaminantes e as oscilações na qualidade d'água, prezando sempre pela sua qualidade.

\section{Referências}

AGUIRRE, J. A. Carta de Uso da Terra da Cidade Universitária - UFSM. Santa Maria: UFSM/CCR /Departamento de Engenharia Rural, 1991. Escala 1:5.000.

BRASIL. Ministério da Saúde. Portaria $N^{\circ}$ 518, de 25 de março de 2004. Atualiza as disposições da Portaria $\mathrm{N}^{\circ}$ 1469, de 29 de dezembro de 2000. Brasília, 2004. Disponível em 〈http://portal.saude.gov.br/portal/arquivos/pdf/portaria_518.pdf>

Acesso em 29 nov. 2008.

D’ÁVILA, R. F. Ensaio metodológico de avaliação de impacto antrópico na bacia hidrográfica da Universidade Federal de Santa Maria - RS. 173f. Dissertação (Mestrado em Engenharia Civil) - Universidade Federal de Santa Maria, Santa Maria, 2009. $173 f$.

FOSTER, S. et al. Proteção da qualidade da água subterrânea: um guia para empresas de abastecimento de água, órgãos municipais e agências ambientais. 2. ed. Washington: Banco Internacional de Reconstrução e desenvolvimento - Banco Mundial, 2003. 114 p.

FOSTER, S.; HIRATA, R. C. A. Determinação de riscos de contaminação das águas subterrâneas: um método baseado em dados existentes. São Paulo: Instituto Geológico, 1993. 87 p. (Boletim, n. 10).

HAUSMAN, A. Províncias Hidrogeológicas do Estado do Rio Grande do Sul - RS. Acta Geologica Leopoldensia (Série Mapas, escala 1:50.000), n. 2, p. 1-127, 1995.

HASSUDA, S. Ciências da Terra em Meio Ambiente: Água Subterrânea um recurso a proteger. São Leopoldo: Água, 1999, p. 179-196.

HIRATA, R. C. A. Recursos Hídricos. In: TEIXEIRA W. et al. (Org). Decifrando a terra. São Paulo: Oficina de Textos, 2000. p 421 - 442. 


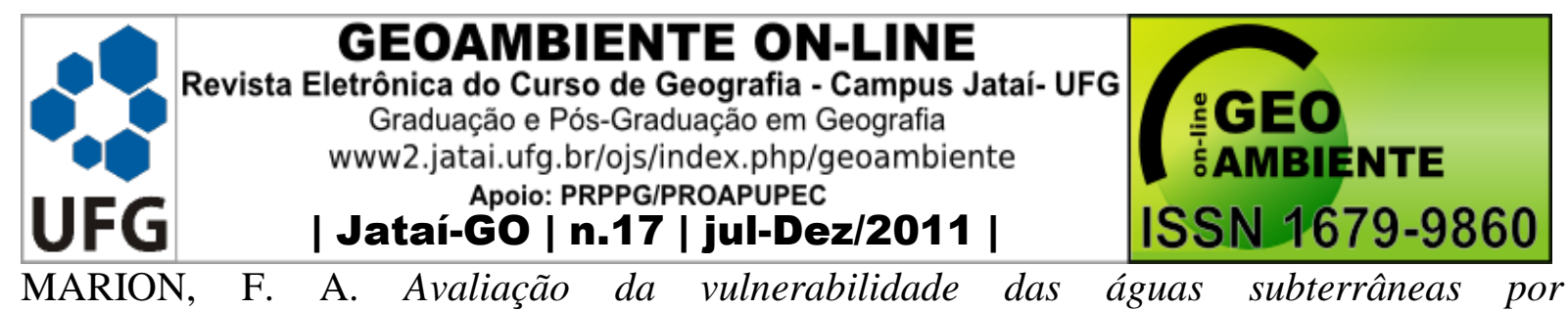

geoprocessamento, no Campus da UFSM - RS. 2009. 94 f. Dissertação (Mestrado em Geomática) - Universidade Federal de Santa Maria, Santa Maria. 94 f.

MOOK, W. G. Isótopos ambientales en el ciclo hidrológico: princípios y aplicaciones. Madrid: IGME, 2002. 596 p. (Publicaciones del Instituto Geológico y Minero de Espana. Séries y Manuales, n. 1)

MOREIRA, C. M. D. Aspectos qualitativos da água subterrânea no Campus da UFSM, Santa Maria - RS. 2005. 174 f. Dissertação (Mestrado em Engenharia Civil) - Universidade Federal de Santa Maria, Santa Maria. $174 \mathrm{f}$.

NIMER, E. Clima. In: Geografia do Brasil: Região Sul. Rio de Janeiro: IBGE, 1990 v. 2. p. 153-187.

ROCHA, G. A. O grande manancial do Cone Sul. Revista Estudos Avançados: Instituto de estudos avançados da USP, São Paulo, v. 11, n. 30, p.191-212, 1997.

SILVA. A. de B. Sistemas de Informações Geo-referenciadas: conceitos e fundamentos. Campinas: UNICAMP, 2003. 236 p.

SILVERIO DA SILVA, J. L. et al. Caracterização de áreas de recarga e descarga do Sistema Aqüífero Guarani em Santana/Rivera e Quaraí/Artigas e estudo da vulnerabilidade natural em Quaraí/Artigas. UFSM/UDeLaR. Santa Maria, 2005. 200p.

XAVIER DA SILVA, J.; Geoprocessamento para análise ambiental. Rio de Janeiro: Ed. do autor, 2001. $227 \mathrm{p}$.

XAVIER DA SILVA, J.; CARVALHO FILHO, L. M. Sistemas de Informação Geográfica: uma proposta metodológica. In: IV Conferência Latinoamericana sobre Sistemas de Informação Geográfica. 2º simpósio Brasileiro de Geoprocessamento, São Paulo, 1993. Anais... 